\title{
PRODUCTION OF MASTITIS IN MICE WITH HUMAN AND BOVINE UREAPLASMAS (T-MYCOPLASMAS)
}

\author{
C. J. HowARD*, J. C. ANDERSON*, R. N. GourlaY* AND \\ D. TAYLOR-ROBINSON $\dagger$ \\ *Institute for Research on Animal Diseases, Compton, nr Newbury, Berkshire, and \\ †Clinical Research Centre, Watford Road, Harrow, Middlesex
}

\section{Plate XLV}

UREA PLASMAS (T-mycoplasmas) (Shepard et al., 1974) of bovine origin cause experimental mastitis in cows (Gourlay, Howard and Brownlie, 1972; Howard, Gourlay and Brownlie, 1973). In contrast, none of six ureaplasma strains of human origin was capable of producing mastitis in cattle (Howard et al., 1973) although two of these strains produced mastitis in goats (Gourlay, Brownlie and Howard, 1973). Cattle and goats, however, are not readily obtainable for experimental work and the use of small laboratory animals would greatly facilitate studies on ureaplasma pathogenesis and immunology. Mastitis has been produced in mice by intramammary inoculation of bacteria obtained from clinical cases of bovine mastitis (Chandler, 1970), and the purpose of this investigation was to determine whether it was possible to produce mastitis in mice with human and bovine ureaplasmas.

\section{MATERIALS AND METHODS}

Ureaplasma strains. Strains derived from the human genital tract, namely nos. CD408, M126/68 and CD573, have been described previously (Howard et al., 1973). Strain CD591 (Johnson) was isolated from the human oropharynx (Taylor-Robinson and Purcell, 1966) and strain T960 is the type strain of Ureaplasma urealyticum (Shepard et al., 1974). Strains A417, Vic9, Bu2 and B101 were isolated from cattle (Howard et al., 1973). Ureaplasmas were grown at $37^{\circ} \mathrm{C}$ in either U3 broth and the corresponding solid medium (Howard et al., 1975) or a PPLO medium described by Taylor-Robinson, Addey and Goodwin (1969). Agarcontaining medium was incubated in an atmosphere of $5 \% \mathrm{CO}_{2}$ in $\mathrm{N}_{2}$.

Assessment of viable ureaplasmas. This was done by determining colour change units (c.c.u.) (Taylor-Robinson and Purcell, 1966; Gourlay et al., 1972), or by determining colonyforming units (c.f.u.).

Mouse inocula. These were prepared either by centrifuging " overnight" broth cultures at $1000 \mathrm{~g}$ for $20 \mathrm{~min}$. and resuspending the deposits in $0.15 \mathrm{M}$ phosphate-buffered saline (PBS) $p \mathrm{H} 7 \cdot 2$, or by thawing from $-70^{\circ} \mathrm{C}$ broth cultures containing a known number of c.f.u. and diluting them in PBS just before use to give the required number of organisms.

Mice. BSVS mice bred at Compton were used, unless otherwise stated. Mice of $\mathrm{C} 3 \mathrm{H}$, CBA and TO strains were bred at the Clinical Research Centre.

Infection and examination of mice. The technique used to inoculate mice by the intramammary route has been described previously (Chandler, 1970); the fourth gland from the front on each side (R4 and L4) was used and the volume of the inoculum was $0.05-0.1 \mathrm{ml}$. 
At necropsy the glands were cut in two, one half being fixed in neutral buffered formalin for histological examination. The other half was ground in $2.5 \mathrm{ml}$ of PBS containing sterile sand, or in PPLO broth by means of a Tenbroeck grinder. The number of mycoplasmas present in each homogenate was determined as c.c.u. and the number present per gland calculated. Homogenates were also spread on to ox-blood-agar plates which were subsequently incubated aerobically at $37^{\circ} \mathrm{C}$ to check for bacterial contamination of the mammary glands.

\section{RESULTS}

Production of experimental mastitis in BSVS mice with Ureaplasma urealyticum, strain $T 960$

Twenty-five lactating mice were given strain T960, suspended in PBS at a concentration of $10^{6}$ c.c.u. per $\mathrm{ml}$, into gland R4, and PBS was inoculated into the left gland (L4) of each mouse. Groups of five mice were killed and examined $1,2,3,4$ and 6 days after inoculation.

The numbers of ureaplasmas in mouse mammary glands are shown in fig. 1. One day after inoculation there was a reduction in the numbers of ureaplasmas present in the glands. Subsequently multiplication occurred and the number of organisms isolated was similar on days 2,3 and 4 after inoculation. By day 6 the number of ureaplasmas in some glands had fallen considerably.

Bacteria, either staphylococci or streptococci, were isolated in small numbers from two glands after the inoculation of ureaplasmas and from five glands after the inoculation of PBS. There was no histological evidence that these bacteria caused an inflammatory response in the glands.

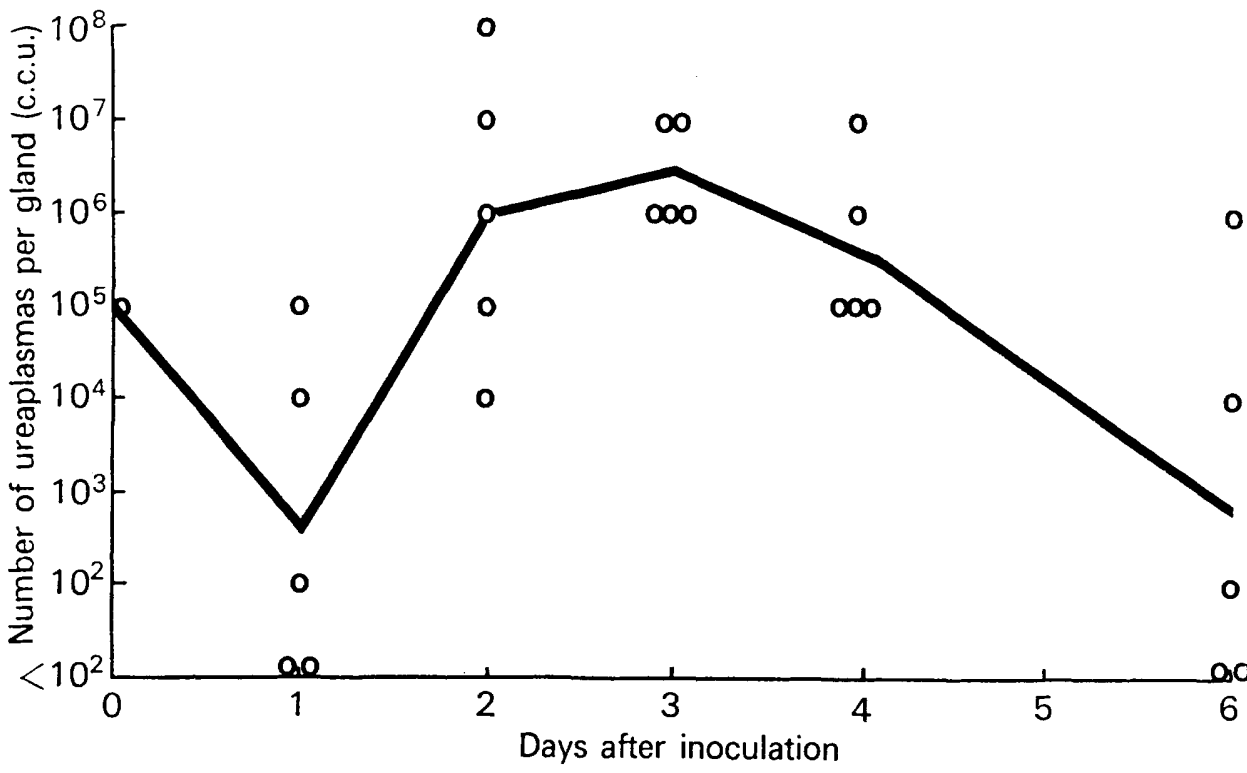

FIG. 1.-Growth of Ureaplasma urealyticum, strain T960, in the mouse mammary gland. Each point indicates the number of organisms isolated from an individual mouse gland inoculated with $10^{5}$ organisms. The line is drawn through the geometric mean of the number of mycoplasmas isolated. 
The mammary tissue was white and full of milk on the day after inoculation and no macroscopical evidence of inflammation was observed. Certain of the glands that had received strain T960 and were examined on days 2, 3 and 4 were slightly redder than the control glands. By day 3 the mammary tissue of both infected and control glands was reduced in size and this was more evident on day 6. No clinical signs of illness were observed in the inoculated mice.

Neutrophils were present in the alveolar lumen of only one of five mammary glands examined 1 day after inoculation, the other glands appearing normal and resembling those that had received PBS. Two days after inoculation, neutrophils, some of which were pyknotic, were found in four of five glands. In addition, the epithelium was vacuolated, the alveoli were reduced in diameter, giving the epithelium a hyperplastic appearance, and there was fat in the interalveolar spaces. In the control glands neutrophils were not observed but there was vacuolation of the epithelium and accumulation of inter-alveolar fat. However, reduction in the alveolar diameter was less marked than in infected glands so that the epithelium did not have a hyperplastic appearance. On day 3 after the inoculation of strain T960, neutrophils and neutrophil debris were present in the ducts and larger alveoli of all glands (fig. 2). Most alveoli were contracted, the lumina were obliterated by the epithelial hyperplasia and in many areas the alveolar outline was lost. Inter-alveolar fat was present in these glands and also in the control glands. Alveolar contraction occurred in the control glands but did not produce a hyperplastic appearance and only colostrum corpuscles were seen in the ducts. On day 4 the glands given strain T960 differed from their controls only in that their ducts contained neutrophil debris and there was greater contraction of alveoli. On day 6 only the presence of neutrophil debris in the ducts distinguished the mycoplasma-inoculated glands from the control glands.

\section{Production of mastitis in BSVS mice with other human ureaplasmas}

Four other human strains, CD408, M126/68, CD573 and CD591 were each inoculated into the R4 glands of five mice which were examined 3 days later. The number of organisms injected was $10^{5}$ c.c.u. and each strain was re-isolated from each mouse. The numbers of organisms recovered (geometric means of c.c.u. per gland) were $10^{7}$ for strain CD591 and $10^{6}$ for the other three strains. Thus there was evidence that all four human strains multiplied in the mammary glands. Furthermore, the histological features were almost identical to those observed 3 days after the inoculation of strain T960.

\section{Production of mastitis in other strains of mice with human ureaplasmas}

Preliminary experiments were designed to see whether other mouse strains were susceptible to infection with human ureaplasmas. Five $\mathrm{C} 3 \mathrm{H}$ mice were given $10^{5}$ c.c.u. of strain T960. Ureaplasmas were isolated from all glands at necropsy 3 days after inoculation, the geometric mean being $10^{6}$ c.c.u. per gland. Strain CD591 (104.7 c.c.u.) was inoculated into the R4 glands of three CBA 
mice. The number of organisms present in the glands at necropsy 2 and 3 days after inoculation was $10^{6}$ or $10^{7}$ c.c.u. A group of TO mice was given $10^{5 \cdot 7}$ c.c.u. of strain CD591. However, at necropsy 4 days later, only $10^{3}$ c.c.u. were isolated from the glands of three mice. The histological changes observed in $\mathrm{C} 3 \mathrm{H}$ and CBA mice were similar to those in BSVS mice.

Comparison of the effect of different ureaplasmas of bovine origin in the mouse mammary gland

The effect of bovine strains A417, Vic9, Bu2 and B101 was compared by inoculating them into two glands, instead of one, in groups of five mice. Doses of $10^{2}, 10^{3}$ and $10^{5}$ c.f.u. were inoculated. The mice were sampled 3 days after inoculation, the time of maximum growth of strain T960 (fig. 1). The number of mice (out of five) and glands (out of ten) infected with each of the three doses are shown in the table. The number of mice and glands colonised by strain B101 appeared less than the number colonised by the other three strains, but little difference was observed between the ability of the other three strains to colonise and grow in the mammary glands.

The geometric means of the numbers of organisms isolated from the infected glands 3 days after inoculation are shown in the table. Multiplication of all strains was apparent after inoculation of $10^{3}$ and $10^{2}$ organisms, except after inoculation of $10^{2}$ c.f.u. of strain B101. About $10^{5}$ organisms per gland were found in mice given $10^{5}$ c.f.u.

Histological sections from infected glands revealed pathological changes similar to those described for mice killed 3 days after strain T960 had been inoculated.

TABLE

Isolation of ureaplasmas from the mammary glands of mice 3 days after inoculation with various doses of four bovine ureaplasmas

\begin{tabular}{c|cccc}
\hline $\begin{array}{c}\text { Strain } \\
\text { no. }\end{array}$ & Inoculum & $\begin{array}{c}\text { *Number of } \\
\text { mice } \\
\text { infected }\end{array}$ & $\begin{array}{c}\text { *Number of } \\
\text { glands } \\
\text { infected }\end{array}$ & $\begin{array}{c}\text { tNumber of } \\
\text { ureaplasmas } \\
\text { per gland }\end{array}$ \\
\hline A417 & $10^{5}$ & 5 & 9 & $10^{5}$ \\
& $10^{3}$ & 5 & 9 & $10^{5}$ \\
Vic9 & $10^{2}$ & 2 & 3 & $10^{4}$ \\
& $10^{5}$ & 5 & 8 & $10^{5}$ \\
& $10^{3}$ & 4 & 7 & $10^{5}$ \\
Bu2 & $10^{2}$ & 3 & 5 & $10^{4}$ \\
& $10^{5}$ & 4 & 8 & $10^{5}$ \\
& $10^{3}$ & 4 & 6 & $10^{5}$ \\
& $10^{2}$ & 4 & 5 & $10^{5}$ \\
& $10^{5}$ & 4 & 8 & $10^{4}$ \\
& $10^{3}$ & 2 & 4 & $\cdots$ \\
\hline
\end{tabular}

* Inoculation was made into groups of five mice, two glands in each mouse.

$\uparrow$ Geometric mean of number of ureaplasmas per gland (c.c.u.). 


\section{Discussion}

The finding that all nine ureaplasma strains, from man and from cattle, produced mastitis in mice after the inoculation of $10^{5}$ organisms contrasts with the results of experiments in other animal species. Although two of the human strains (CD573 and CD408) produced mastitis in goats, human strain M126/68 did not (Gourlay et al., 1973) and none of these three human strains caused experimental mastitis in cattle (Howard et al., 1973). Furthermore, of the four bovine strains, two (nos. A417 and Vic9) caused mastitis in cattle but the other two (nos. Bu2 and B101) did not (Howard et al., 1973). Thus, mice of the BSVS strain, and apparently those of other strains too, develop mastitis after inoculation of ureaplasmas more readily than do either cattle or goats. It seems, therefore, that the inability of all five human strains to produce mastitis in cows is not because of avirulence per se. While the production of mouse mastitis emphasises the pathogenic potential of human strains, the present experiments have not, of course, thrown any light on the controversial question whether these strains affect the genital tract of man (Shepard et al., 1974). It would be surprising if further work failed to reveal that different human strains affect the mouse mammary gland in slightly different ways. If this were so, it would then be feasible to see whether strains associated with non-specific urethritis in man had a greater pathogenicity for mice than strains apparently unassociated with human disease.

The number of ureaplasmas isolated from glands during the first 2 days after inoculation with strain T960 varied considerably from mouse to mouse. This may reflect the differing ability of mice to deal with inoculated organisms in the early stages of infection. It is possible that humoral mycoplasmacidal factors, similar to those found in bovine whey (Brownlie, Howard and Gourlay, 1974; Howard et al., 1975) might be involved in host defence at this stage of the infection, particularly as neutrophils were found in the glands of only one of five BSVS mice $24 \mathrm{~h}$ after inoculation with $U$. urealyticum T960.

A leucocyte response in the udder of the cow can be produced readily and rapidly by injecting a relatively mild irritant (Derbyshire and Berman, 1968). Further, Gourlay et al. (1972) showed that there was a significant transient neutrophil response of the bovine udder to intramammary injection of dead mycoplasmas and of sterile broth and this response would obscure a neutrophil response to an infection with live mycoplasmas, if one occurred, in the first few days after inoculation. The mouse mammary gland is less sensitive to mild irritants (Anderson, 1971) and the neutrophil response to mycoplasmas was not evident until $48 \mathrm{~h}$ after infection. This is in contrast to experimental staphylococcal mastitis in the mouse in which a neutrophil response occurred within $6 \mathrm{~h}$ of inoculation (Anderson and Chandler, 1975). Thereafter, the histopathological changes induced by ureaplasmas, namely vacuolative epithelial hyperplasia and involution, were similar to those induced by a strain of Staphylococcus aureus of low virulence (Anderson, 1974) though slower in development. However, staphylococcal and ureaplasmal mastitis differed in that inoculation with ureaplasmas did not result in abscess formation. 
In our experiments, offspring were removed at the time of inoculation and mammary glands underwent involution. If the offspring are allowed to remain, they do not suck glands into which inoculation has been made and involution still occurs. In cows and goats, on the other hand, lactation continues long after inoculation with ureaplasmas. Thus the cow and goat udders are continually washed through with milk. In the mouse this does not occur and the continued presence of the ureaplasmas may be one reason for the increased susceptibility of mice. In the mouse, attachment to cells may not be as important a requirement for virulence as in the cow or goat. Also, in cattle the severity of the mastitis reaches a peak about 8 days after inoculation with ureaplasmas, whereas in the mouse less than $1 \%$ of lactation tissue remains 8 days after removal of offspring (Anderson, unpublished). Thus, although the mouse model may provide a means of studying several aspects of ureaplasma infection, in particular immunological ones, the initial stages of infection may prove to be the most usefully studied.

\section{SUMMARY}

Five ureaplasmas (T-mycoplasmas) of human origin and four of bovine origin were inoculated into the mammary glands of mice. The strains multiplied and neutrophils were observed in sections of infected glands. Some of the glands were macroscopically inflamed, albeit slightly, at necropsy but none of the mice showed any sign of disease during the course of the experiments. All nine ureaplasma strains produced mastitis in BSVS mice and the mammary glands of mice appear more susceptible to ureaplasmas than the udders of cows or goats. Mouse mastitis is suggested as being a suitable small animal model for studying ureaplasma infections.

We thank Mrs J. Collins and Miss P. M. Furr for their technical assistance.

\section{REFERENCES}

ANDERson, J. C. 1971. Observations on mouse mastitis produced by inoculation of different strains of staphylococcus. Res. vet. Sci., 12, 186.

ANDERSON, J. C. 1974. Experimental staphylococcal mastitis in the mouse: effects of extracellular products and whole bacterial cells from a high-virulence and a lowvirulence strain of Staphylococcus aureus. J. med. Microbiol., 7, 205.

ANDERson, J. C. AND CHANDleR, R. L. 1975. Experimental staphylococcal mastitis in the mouse: histological, ultrastructural and bacteriological changes caused by a virulent strain of Staphylococcus aureus. J. comp. Path. (in press).

Brownlie, J., Howard, C. J. AND Gourlay, R. N. 1974. Mycoplasmacidal activity of bovine milk for T-mycoplasmas. J. Hyg., Camb., 73, 415.

ChandLeR, R. L. 1970. Experimental bacterial mastitis in the mouse. J. med. Microbiol., $3,273$.

Derbyshire, J. B. AND Berman, D. T. 1968. Leukocytic responses of the bovine udder to infusion of certain irritants. Am. J. vet. Res., 29, 1971.

Gourlay, R. N., Brownlie, J. AND Howard, C. J. 1973. Isolation of T-mycoplasmas from goats, and the production of sub-clinical mastitis in goats by the intramammary inoculation of human T-mycoplasmas. J. gen. Microbiol., 76, 251.

Gourlay, R. N., Howard, C. J. AND BRownlie, J. 1972. The production of mastitis in cows by intramammary inoculation of T-mycoplasmas. J. Hyg., Camb., 70, 511. 
EXPERIMENTAL UREAPLASMA MASTITIS IN MICE
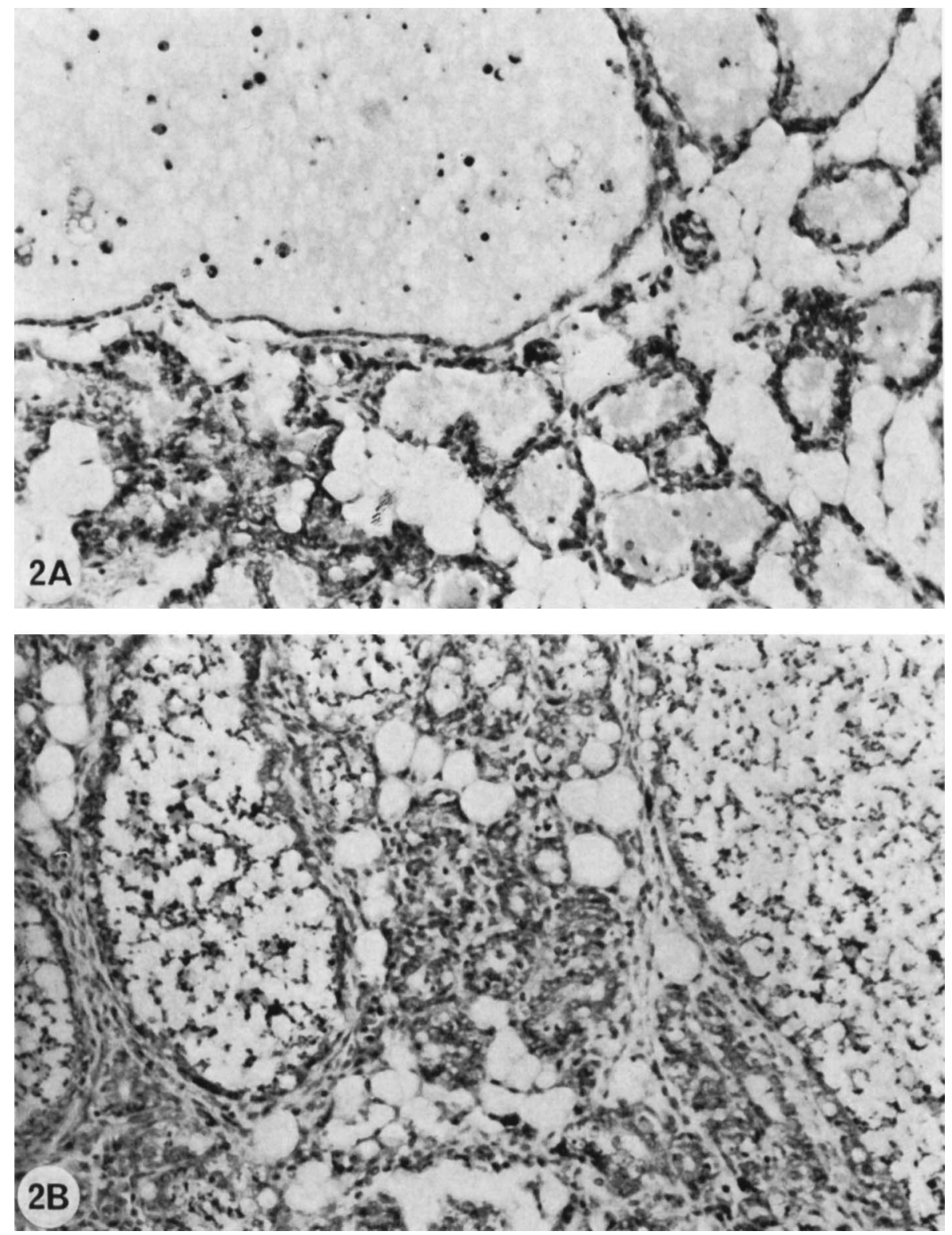

FIG. 2(a).-Normal mouse mammary gland 3 days after inoculation of phosphate-buffered saline.

FIG. 2(b).--Mouse mammary gland 3 days after inoculation with Ureaplasma urealyticum strain T960. Note debris in ducts and loss of alveolar architecture in infected gland. Giemsa. $\times 138$. 
Howard, C. J., Brownlie, J., Gourlay, R. N. and Collins, J. 1975. Presence of a dialysable fraction in normal bovine whey capable of killing several species of bovine mycoplasmas. J. Hyg., Camb., 74, 261.

Howard, C. J., Gourlay, R. N. AND Brownlie, J. 1973. The virulence of T-mycoplasmas isolated from various animal species, assayed by intramammary inoculation in cattle. J. Hyg., Camb., 71, 163.

Shepard, M. C., Lunceford, C. D., Ford, D. K., Purcell, R. H., Taylor-Robinson, D., RAZIN, S. AND BLACK, F. T. 1974. Ureaplasma urealyticum gen. nov., sp. nov.: proposed nomenclature for human $\mathrm{T}$ (T-strain) mycoplasmas. Int. J. syst. Bact., 24, 160.

TAYloR-Robinson, D., ADDEY, J. P. AND Goodwin, C. S. 1969. Comparison of techniques for the isolation of T-strain mycoplasmas. Nature, Lond., 222, 274.

TAylor-Robinson, D. AND Purcell, R. H. 1966. Mycoplasmas of the human urogenital tract and oropharynx and their possible role in disease: a review with some recent observations. Proc. R. Soc. Med., 59, 1112. 